\title{
Multidisciplinary treatment of gastrointestinal stromal tumors
}

\author{
T. Peter Kingham, M.D. ${ }^{a}$ and Ronald P. DeMatteo, M.D. ${ }^{b}$ \\ aFellow, Department of Surgery, Memorial Sloan-Kettering Cancer Center, New York, NY \\ bVice Chair, Department of Surgery, Memorial Sloan-Kettering Cancer Center, New York, NY
}

\author{
Keywords \\ gastrointestinal stromal tumors; diagnosis; treatment
}

\section{Introduction}

Gastrointestinal stromal tumor (GIST) is the most common mesenchymal tumor of the gastrointestinal tract. Although rare as a clinical entity, there is much interest in their pathology and treatment because the KIT protooncogene mutation common to most GISTs can be inhibited by imatinib mesylate (Gleevec ${ }^{\mathrm{TM}}$; Novartis Pharmaceutical, Basel, Switzerland). The utility of imatinib has marked a new era in treating solid tumors, with specific therapeutic molecular targeting. Diagnosing and treating GIST requires a multidisciplinary approach, given the combination of pathologic and radiographic evaluation, surgical treatment, and oncologic care required to successfully treat patients with GIST.

GIST has been recognized as a unique tumor only in the last decade. Originally, GISTs were thought to be derived from smooth muscle cells, and were considered variations of leiomyosarcomas or leiomyomas. Immunohistochemical staining assisted in defining GIST as a distinct disease based on KIT(CD117) expression (found in 95\% of GIST). Plateletderived growth factor receptor alpha (PDGFRa) mutations have since been found in about $5 \%$ of GISTs that lack KIT expression.

\section{Epidemiology}

GISTs affect men more than women. They constitute $80 \%$ of all gastrointestinal mesenchymal tumors and approximately $20 \%$ of all small bowel malignant neoplasms, excluding lymphomas. It is difficult to judge the historical incidence of GIST. A populationbased study in Sweden reported an incidence of approximately 13 cases per million persons per year. ${ }^{1}$ Extrapolating from this, it is believed the U.S. incidence is 3,000 to 5,000 cases per year. GISTs generally occur in older adults, between 40 and 80 years of age..$^{2-6}$ The median age at diagnosis is approximately 60 . GIST can occur in children, especially

Corresponding author: T. Peter Kingham, M.D., Dept. of Surgery, Memorial Sloan-Kettering Cancer Center, 303 E. $60^{\text {th }}$ St., Apt 28E, New York, NY 10022, kinghamt@mskcc.org, 917-886-4045.

Coauthor address: Ronald P. DeMatteo, M.D., Vice Chair, Dept. of Surgery, Memorial Sloan-Kettering Cancer Center, 1275 York

Avenue, Box 203, New York, NY 10065, dematter@mskcc.org, 212-639-3976 
females, and typically has lymph node metastasis, gastric location, and wild-type KIT/ PDGFRa genotype. ${ }^{7}$

GIST is usually sporadic, although there are recognized kindreds with familial GIST throughout the world. Most familial GIST have a germline KIT mutation in exon $11 .^{8}$ GIST can occur in young females in the context of "Carney's triad." This rare syndrome occurs in young women and includes functioning extra-adrenal paragangliomas, pulmonary chondromas, and gastric GIST. GIST can also occur in patients with the Neurofibromatosis type-1 (NF1) syndrome, and these GIST usually are found in the small intestine. The origin of these GISTs may be different than sporadic GIST, due to the lack of identified KIT or PDGFRa mutations in patients with NF1.

\section{Molecular Basis of Disease}

GISTs are related to the interstitial cells of Cajal. Their behavior ranges from benign to malignant, and there are several histologic subtypes including spindle cell (70\%), epithelioid (20\%), and pleomorphic types. ${ }^{9}$ Ninety five percent of GISTs have gain-of-function KIT mutations or PDGFRa mutations. KIT encodes for a transmembrane receptor glycoprotein with tyrosine kinase function and normally participates in cell growth and survival. Most KIT mutations cause ligand-independent activation of the receptor tyrosine kinase function. Identifying KIT and PDGFRa mutations are useful for both the diagnosis and treatment of GIST. KIT mutations occur most frequently in exon $11(70 \%)$, the juxtamembrane domain of the KIT protein. Mutations can also occur in exon 9 (10\%), the extracellular domain of the $K I T$ protein. It is helpful to identify the location of the KIT mutation, given that exon 9 mutant GISTs do not respond as well to imatinib as exon 11 mutant GISTs. Rarely, KIT exon 13 and 17 mutations can occur. These locations, in addition to exon 14, are also areas of mutation in GIST that can be associated with imatinib resistance.

Approximately 5\% of GISTs do not express the KIT protein. In the 3\% of GIST with PDGFR a mutations, the mutation is generally present in exon 18 (80\%) or exon 12 . PDGFR $a$ mutations are more common in gastric GISTs. The location of the PDGFRa mutation is important given that most exon 18 mutant GISTs are resistant to imatinib, while the exon 12 mutant GISTs are sensitive to imatinib. GISTs that do not have identifiable mutations are considered wild-type and their pathogenesis is unclear.

\section{Malignancy and GIST locations}

GIST behavior occupies a wide spectrum from benign to malignant. Malignancy is most common in intestinal GIST (40\%) and lowest in gastric GIST (20\%). GISTs occur from the esophagus to the anus. Gastric GISTs are the most common (60\%), and have many different forms and mutations. Treatment ranges from wedge resection to total gastrectomy, depending on the location. Gastric tumors can adhere to surrounding structures in the lesser sac such as the pancreas and transverse colon. Duodenal GISTs occur most commonly in the second portion. They resemble small intestine GISTs histologically. 30\% of GISTs are in the jejunum or ileum, and ileal tumors are slightly less common than jejunal tumors. ${ }^{10}$ GIST can also occur in the rectum, but rarely in the colon.

Surg Clin North Am. Author manuscript; available in PMC 2016 September 02. 


\section{Clinical Presentation}

The clinical presentation of GIST often depends on its size and location. GIST may not induce symptoms and can be found incidentally during physical examination or during an invasive procedure. When symptoms do arise, they generally are due to mass effect, given the extraluminal location of GIST. The mean duration of symptoms, is 4-6 months. In Sweden, approximately $70 \%$ of GISTs were associated with symptoms. ${ }^{1}$ The median size of GIST in those with symptoms was $8.9 \mathrm{~cm}$ compared to $2.7 \mathrm{~cm}$ in those who were asymptomatic. Most symptoms consisted of nausea, emesis, pain, early satiety, or abdominal distension. Patients can present with microcytic anemia and fatigue when GISTs erode into the intestinal tract lumen and cause subclinical GI bleeding. Up to $25 \%$ of patients with GIST can present with significant bleeding, either caused by erosion into the GI tract or intra-peritoneal rupture.

\section{Diagnosis}

GISTs are often diagnosed only after resection and pathological examination. Imaging has become more common in the evaluation of patients with abdominal symptoms, so contrastenhanced computed tomography (CT) scans and magnetic resonance imaging (MRI) are more frequently able to suggest the diagnosis of GIST. On MRI, GISTs have low signal intensity on T1-weighted images, high intensity on T2-weighted images, and enhance with gadolinium contrast. ${ }^{11}$ GISTs usually involve the muscularis propria of the gastrointestinal wall, so the characteristic image is that of a well-circumscribed, smooth, intramural mass with exophytic growth. The organ of origin can be often identified by focal mural thickening. Smaller primary GISTs are usually well circumscribed with neo-vascularity and are associated with the stomach or small intestine. Larger GISTs $(>10 \mathrm{~cm})$ have borders of various thickness and can have heterogeneous central areas of necrosis or hemorrhage. As gastric GISTs enlarge, they extend into the gastrohepatic, gastrocolic, or gastrosplenic ligament. Small intestine GIST can extend into the small bowel mesentery as they grow, which can make preoperative diagnosis difficult due to similarities with lymphoma and other sarcomas. Axial imaging also allows for evaluation of the liver and peritoneum, the most common sites of metastasis. Given the rarity of metastatic spread to the thorax, a chest radiograph is adequate to assess the thorax for metastatic disease. Lymphatic spread is rare with metastatic GIST, so lymphadenopathy is generally not encountered on physical exam or imaging studies. ${ }^{12}$ Staging of GIST relies primarily on CT imaging. CT supplies the necessary information to determine whether surgical resection is feasible. ${ }^{18}$ Fluorodeoxyglucose (FDG) positron emission tomography (PET) uptake is sensitive, but not specific, when used to diagnose GIST. It is generally not necessary in most patients, but can be used as an early test of treatment response (Figure 1). ${ }^{13}$

Once the diagnosis of GIST has been suggested on axial imaging, endoscopy can be useful to determine the presence of a gastric or colorectal submucosal mass. Endoscopic ultrasound can delineate the full depth of the tumor, although it is not able to predict tumor behavior. Preoperative biopsy is generally not indicated for several reasons. First, GISTs $\underline{s}$ are fragile and can theoretically rupture and spread tumor cells when biopsied. Second, given their hypervascular nature, a biopsy can cause intratumoral hemorrhage. Perhaps most important, 
pathologists often can not diagnose GIST from fine needle aspirates, especially when the area sampled is necrotic. Endoscopic biopsy is less likely to cause hemorrhage, and is useful only to confirm the diagnosis, exclude the diagnosis of lymphoma which can have a similar radiologic appearance, or allow for neoadjuvant imatinib therapy for a marginally resectable tumor.

\section{Pathologic diagnosis and prognosis}

In the multidisciplinary approach to diagnosing and treating patients with GIST, pathologic review plays a central role in initiating treatment algorithms. Determining KIT receptor positivity on immunohistochemistry is vital. Other immunohistochemical characteristics used in the diagnosis of GIST are CD34, a hematopoietic progenitor cell antigen (present in 60 to $70 \%$ of GIST), smooth-muscle actin (30-40\%), and S-100 protein (5\%). ${ }^{14}$ On rare occasions, GIST can express desmin, similar to smooth muscle tumors, but it is generally isolated to small focal areas of the tumor. ${ }^{9}$ In KIT-negative tumors, protein kinase $\mathrm{C}$ theta, a protein kinase activated downstream in the KIT pathway, may be useful to differentiate GIST from other tumor types, given its predilection for GIST. ${ }^{15}$

The prognosis of GIST is quite variable. The stage of disease is significant, demonstrated by a lower survival in patients with metastatic disease. ${ }^{2}$ The most pertinent variables that affect the prognosis of primary, non-metastatic GIST, are tumor site, size, and number of mitoses (per 50 high power fields, Table 1). All GISTs are potentially malignant, except perhaps small $(<1 \mathrm{~cm})$ tumors. In one historical series from Memorial Sloan-Kettering Cancer Center (MSKCC), multivariate analysis demonstrated the significance of tumor size as an independent prognostic factor of survival. In patients with large GIST (greater than $10 \mathrm{~cm}$ ), the 5 year actuarial survival was only 20\% (Figure 2). Similar findings were reported by MD Anderson Cancer Center (MDACC). ${ }^{16}$ The importance of tumor size is also demonstrated by a high tumor-related mortality seen with GIST larger than $5 \mathrm{~cm}$ and with a mitotic rate greater than 5 per 50 high power fields (HPF). Median survival can be 1 to 2 years in this subset of patients, in the absence of tyrosine kinase inhibitor therapy. Mitotic rate and tumor location are also predictors of outcome in patients with GIST. ${ }^{7}$ GIST of the stomach are less aggressive than GIST in other locations. Gastric tumors less than $5 \mathrm{~cm}$ with less than 5 mitoses per 50 HPF have a lower than $2 \%$ rate of malignancy, compared to GIST with similar mitotic rates in other anatomical sites which have higher rates. ${ }^{17}$ Long term follow up for GIST is necessary because there is an unpredictable metastatic pattern. Small tumors have been known to metastasize 10 years after diagnosis.

Whether a KIT mutation is present, and what type of mutation it is, are also prognostic. Recurrence after primary resection is more common in patients with a deletion/insertion mutation of exon $11 .{ }^{18}$ GIST with regulatory type mutations in the juxtamembrane and extracellular ligand binding domains that leave the enzymatic site that binds to imatinib intact respond to imatinib. GIST with an enzymatic site mutation can alter the sequence of the kinase catalytic moiety and thus prevent effective response to imatinib. ${ }^{19}$ In addition to these variables, alternative prognostic factors have been studied. Tumor rupture before or during resection predicts a poor outcome and increased peritoneal recurrence. ${ }^{16}$ The completeness of resection and tumor size have also been correlated with survival. ${ }^{20,21}$ 
Aneuploidy has been identified as another marker of malignancy. ${ }^{22,23}$ Telomerase expression has been identified in 29\% of a cohort of 24 patients with primary GIST and all patients with metastatic disease. ${ }^{16}$ Despite all of the prognostic variables that have been identified for GIST, it remains difficult for pathologists to confidently identify benign GIST. Instead, pathologists often characterize GIST as low or high risk for malignancy. ${ }^{24}$ Commonly accepted guidelines for classifying a GIST as malignant are size greater than $5-10 \mathrm{~cm}$, with more than 5 mitoses per $50 \mathrm{HPF}$.

While there are many predictors for the malignant potential of primary GIST, there are few predictors of the site of first recurrence. There are several studies that have looked at historical data to describe recurrence patterns. At MSKCC, the first recurrence in patients with complete resection of a primary GIST was the peritoneum (52\%), liver (63\%), or both $(15 \%){ }^{2}$ Similar findings were described from MDACC, with approximately $40 \%$ of recurrences identified as peritoneal. ${ }^{25}$ The only reliable predictor appears to be tumor rupture, which leads to a higher peritoneal metastasis rate. Overall survival at five years for patients with GIST at MSKCC was 35\%. ${ }^{2}$ The 5 year disease-specific survival in patients with a primary GIST who undergo complete resection ranges from 40 to $65 \%$. $2,16,26,27$ This decreases to 9-12 months in patients with incomplete resections. ${ }^{2,}{ }^{26}$ Peritoneal disease occurred in $52 \%$ of patients, with a 2 year median time to recurrence after a complete resection. ${ }^{2,16}$ Median survival in patients with a local recurrence was 12 months, and in patients with metastases was 19 months. While approximately half of all patients who undergo complete resection survive more than five years, given the high local and distant recurrence rate, adjuvant therapy is now a key factor in successful long term treatment of GIST.

\section{Treatment}

Imatinib mesylate is the first targeted small molecule inhibitor used for solid tumors. It competitively inhibits the KIT, PDGFRa, and $B C R-A B L$ kinases. By binding to the ATPbinding pocket of the kinases, it blocks the transfer of a phosphate group to the substrate, and thus blocks the transduction of signals initiated by KIT or PDGFRa activation. For imatinib to bind effectively, the activation loop of the kinase (encoded on KIT exon 17) must be in an inactive conformation. ${ }^{28}$ Imatinib is metabolized in the liver via the cytochrome P450 pathway. Fifty to $70 \%$ of patients with GIST have a partial response to imatinib, and $15-30 \%$ are maintained with stable disease. ${ }^{29,30}$ Tumor volume reduction occurs at a median of 3-4 months. PET scan with ${ }^{18}$ FDG can reveal diminished uptake within days of imatinib treatment. ${ }^{31}$ The location of the KIT or PDGFR $a$ mutation can predict response to imatinib. KIT exon 11 mutations are the most sensitive to imatinib treatment. Approximately $70-80 \%$ of these patients undergo partial remission, compared to $40-50 \%$ with exon 9 mutation. ${ }^{30,} 32$ 'Wild-type GIST, without a recognized KIT or PDGFR $a$ mutation have a lower response rate (23-39\%) to imatinib that patients with KIT exon 11 mutations. ${ }^{30,33}$ Given these findings, regardless of the KIT or PDGFRa mutation status, imatinib is the first line treatment of metastatic GIST. One of the few exceptions to this is in GIST with PDGFRa exon $18 \mathrm{D} 842 \mathrm{~V}$ mutations that are known to be resistant to imatinib. ${ }^{34}$ 
Imatinib should be administered without interruption. This was demonstrated in a study of 58 patients with metastatic or unresectable GIST who had stable or responsive disease after 1 year of treatment with imatinib and were followed in a prospective multicenter trial that randomized them to discontinue imatinib. ${ }^{35}$ Patients randomized to the interrupted arm were able to cross over to the treatment arm if their disease progressed. Eighty one percent of patients in the interrupted group had disease progression in a median evaluation period of 21 months compared to $31 \%$ of patients in the continuous treatment group. Ninety two percent of patients who had disease progression in the interrupted group responded to imatinib when it was restarted. Reported side effects of imatinib are diarrhea, nausea, abdominal pain, fatigue, and rash. Approximately $95 \%$ of patients tolerate treatment.

\section{Primary Resectable Disease}

Surgery has traditionally been the cornerstone of treatment for resectable GIST. In the postimatinib era, surgery shares a role in a multidisciplinary treatment plan (Figure 3). In primary disease, complete surgical resection provides the chance of cure (Table 2). There are several important principles that guide surgical resection. Since GIST can be fragile with extensive necrosis or hemorrhage, meticulous dissection is vital to avoid tumor rupture during the procedure, which can increase the risk of intraperitoneal recurrence. GISTs are normally surrounded by a pseudocapsule that should be intact after resection. Given the normal exophytic growth pattern of GIST within the gastrointestinal tract, wedge or segmental resections are often possible. GISTs adhere to surrounding structures, so additional organ resections may be required for complete resection. Margins of resection should be microscopically negative. To achieve this, a $1 \mathrm{~cm}$ gross margin is generally sufficient. A positive microscopic margin forces the surgeon to consider whether the margin is truly positive and decide if it can be identified and resected a second time. Laparoscopy is a useful modality to resect small gastric GIST, especially since lymphadenectomy is rarely required.

Complete resection is possible in $85 \%$ of patients with primary GIST. ${ }^{2,3,6}$ In completely resected GIST, the microscopic margin is negative in 70-95\% of cases. ${ }^{2}$ At MSKCC, 80 of 93 patients (86\%) with primary disease and no metastases were able to undergo complete resection. In these 80 patients, before the advent of imatinib, the 5-year disease-specific survival was $54 \%$ (Figure 4). $40 \%$ of the patients in this study had a recurrence. Other studies report $26 \%$ to $44 \%$ recurrence rates. ${ }^{3-5}$ There are no standard protocols for postoperative follow up after complete resections. Given that imatinib is now available for use in treating recurrences, routine axial imaging is an integral part of postoperative follow up. Current recommendations are CT scans with intravenous contrast every 3-6 months for the first 5 years, and then yearly after that. ${ }^{36}$

The role of imatinib therapy in completely resected primary GIST is becoming clearer. The American College of Surgeons Oncology Group (ACOSOG) is leading a Phase II intergroup trial (Z9000) in combination with Novartis and the Cancer Therapy Evaluation Program. They are examining the effect of adjuvant imatinib (400mg/day for 12 months) after complete macroscopic resection in patients with high-risk primary GIST ( 25 tumors, tumor size $\geq 10 \mathrm{~cm}$, or intraperitoneal tumor rupture or hemorrhage). One hundred and six patients 
accrued to this trial and were treated with imatinib (400mg/day) for 1 year. The trial completed accrual in 2003 and $83 \%$ of patients completed the year of imatinib therapy. ${ }^{37}$ At 4 years of median follow-up, overall survival rates were $97 \%$ at 3 years, with the conclusion that 1 year of imatinib post-resection led to improved overall survival compared to historical controls. ${ }^{38}$ A separate ACOSOG trial (Z9001) also studied the use of imatinib compared to placebo in patients with completely resected primary GIST that are at least $3 \mathrm{~cm}$. The primary end-point of the double blinded study was recurrence-free survival. The trial was halted after a median follow-up of 13-14 months due to the significant difference in recurrence free survival between the study group (97\%) and placebo group (83\%). ${ }^{39}$ The EORTC is also conducting a study that is looking at 24 months of adjuvant imatinib compared to observation in patients at either intermediate or high risk of recurrence.

\section{Primary unresectable GIST}

When primary GIST appears to be unresectable or borderline, imatinib is the treatment of choice. A CT scan 1 month after initiation of imatinib is useful to judge tumor response, and thus potential resectability. One Phase II trial by the Radiation Therapy Oncology Group (RTOG) is investigating the use of imatinib in the neoadjuvant setting when primary tumors are large and may require additional organ resection to achieve negative margins. In these trials, patients are treated with imatinib for 2-6 months prior to surgery. CT scans are used to judge the effectiveness of the imatinib, and surgical resection is generally performed within 6-9 months. An additional benefit may be decreased blood loss, given the hypervascularity of large GIST. One of the risks of neoadjuvant therapy is that a needle biopsy is necessary to begin treatment. Given that $15 \%$ of patients have primary resistance to imatinib, there is also a risk that the tumor will become unresectable due to the delay in surgical intervention.

\section{Recurrent and metastatic GIST}

Recurrent and metastatic GIST are managed in a similar fashion. Surgery alone is limited in its value in treating recurrent GIST. Peritoneal metastases can be removed, but are generally followed by another regional recurrence. In addition, only $26 \%$ of liver recurrences are resectable, and most patients develop recurrence after hepatectomy. ${ }^{40}$ The first line of treatment in patients with recurrent and metastatic disease is imatinib (Table 3). Initial response can be followed with CT scans or by ${ }^{18}$ FDG-PET response. Life-long treatment with imatinib is recommended in patients with imatinib-responsive GIST, given that it decreases the likelihood of disease progression. Approximately $45 \%$ of patients with metastatic GIST have a partial response to imatinib, while 30\% maintain stable disease. ${ }^{29,41,42}$ The success of imatinib is evident in that median survival was only 15 months after resection of recurrent GIST in the pre-imatinib era, while the median overall survival with metastatic disease is now 5 years. ${ }^{29,43}$ The normal starting dose of imatinib is $400 \mathrm{mg} /$ day. Although there is no difference in overall survival between 400 and $800 \mathrm{mg} /$ day, one study does suggest there may be longer progression-free survival with twice daily imatinib. $^{29}$

Due to the response to imatinib in many patients with metastatic GIST, and since imatinib is not curative, there is often a role for surgery in addition to tyrosine kinase inhibition. 
Combining the two modalities may delay imatinib resistance and potentially be curative ${ }^{44,}{ }^{45}$ Current practice at MSKCC is to treat patients with imatinib for 3-6 months and then consider surgery if complete resection is suggested on imaging. Patients are then treated with postoperative imatinib to prevent recurrence. In 40 patients with metastatic GIST treated with imatinib, three subgroups were identified at the time of surgery. One group had responsive disease, another focal resistance, and the third had multifocal resistance. The median time of imatinib therapy was 7, 21, and 26 months, respectively (Figure 5). Grossly negative margins were achieved in $85 \%, 46 \%$, and $29 \%$ of patients, respectively. Multiple organ resections were involved in the surgery, including peritoneum $(68 \%)$, stomach or intestine (48\%), liver (43\%), and the pancreas (13\%). After a median follow-up of 15 months, there was a significant difference in progression-free survival between the groups. While there are many potential biases confounding these results, before randomized trials can assist in providing additional data, this study does suggest that patients with imatinib responsive disease or only focally progressive disease should be considered candidates for surgical resection.

\section{Imatinib-resistant GIST}

Imatinib resistance can develop after long term treatment. Often resistant GISTs develop a secondary KIT mutation at the gene that encodes parts of the kinase that are integral for imatinib binding. Approximately half of secondary mutations occur in KIT exon 17 and interfere with imatinib binding. ${ }^{30}$ The other half of mutations responsible for imatinib resistance can involve, activation of other kinases, increased imatinib metabolism, or rarely target gene amplification. Approximately 50\% of GIST that progress do so in only one resistant tumor nodule that exists within or next to responding areas of metastasis. In one study, 8 of 10 such "nodules within a mass" developed a new KIT mutation that was not present at diagnosis. ${ }^{46}$ In scenarios when one nodule continues to grow, while the majority of metastatic disease responds to imatinib therapy, surgical resection of the resistant nodule should be considered. Months to years of disease control may be provided after resecting the resistant tumor and continuing imatinib therapy, especially when the primary GIST was gastric in origin. ${ }^{47}$

In patients who have GIST that progresses while on imatinib at a dose of $400 \mathrm{mg} / \mathrm{day}$, the dose can be escalated to $800 \mathrm{mg} /$ day. Five percent of patients who progress at $400 \mathrm{mg} / \mathrm{day}$ will respond to the elevated dose of imatinib and achieve at least partial remission. ${ }^{48}$ Additionally, 30\% of patients will have stable disease. In patients who have imatinibresistant GIST or who do not tolerate imatinib, sunitinib is the next line of therapy. It is a multi-targeted tyrosine kinase inhibitor that has both antitumor and antiangiogenic abilities. Its mechanism involves inhibition of vascular endothelial cell growth factor receptors 1, 2, and 3, KIT, PDGFRa, PDGFR $\beta$, Fms-like tyrosine kinase-3 receptor, and the ret protooncogene receptor. One prospective, randomized, placebo-controlled trial examined 312 patients with imatinib resistance or intolerance. ${ }^{49}$ They reported a median time to tumor progression of 6.4 weeks in the placebo group and 27.3 weeks in the sunitinib group. 58\% of patients treated with sunitinib had stable disease, compared to $48 \%$ of patients treated with placebo. The end result, even after crossover of patients from the placebo group to the treatment arm, was significantly longer overall survival in patients treated with sunitinib. 
There are several other treatment modalities available, including radiation, ablation, and some novel agents. GIST are considered radiation-resistant tumors, and there are no prospective trials of the effect of radiation therapy. ${ }^{50}$ The only role for radiation therapy is for palliative treatment or possibly with rectal GIST. Radiofrequency ablation (RFA) is a technique that is now being used more frequently with metastatic GIST in the liver. There are limited data suggesting its benefit, but based on other types of tumors in the liver, it is possible to use RFA on lesions smaller than $3 \mathrm{~cm} .{ }^{51}$ RFA is generally not performed with more than 3-5 tumors, and can be used with stable or progressive disease during imatinib treatment. Hepatic artery embolization can also be useful to palliate patients with liver metastases, because the tumors are often hypervascular. In patients with diffuse hepatic metastases, half of the liver can be treated at a time. Despite its success in reducing tumor volume with metastatic GIST, there is no evidence that it improves survival. ${ }^{52,53}$

The results of treatment with traditional chemotherapy have not been successful. ${ }^{54}$ Specifically, treatment with doxorubicin or gemcitabine combinations has resulted in less than a $10 \%$ response rate. ${ }^{55,56}$ Similarly, there was no response to ifosfamide and etoposide or temozolomide in patients with metastatic GIST. ${ }^{57,58}$ Given the failure of traditional chemotherapy agents to treat GIST, after resistance or intolerance to imatinib and sunitinib, there are several other tyrosine kinase inhibitors that are currently being studied. Vatalanib (PTK787/ZK222584) has a similar mechanism of action to sunitinib and has been shown to have effect on imatinib-resistant GIST. ${ }^{59}$ Dasatinib (BMS354825) is another tyrosine kinase inhibitor that may have utility in GIST with an exon 17 mutation and imatinib resistance. It also inhibits the src kinase, which is a downstream kinase that can be activated after KIT activation. Everolimus is another agent currently being studied. It inhibits the PI3K-Aktmammalian target of rapamycin (mTOR) pathway that is activated by the KIT receptor tyrosine kinase. ${ }^{60}$

\section{Conclusion}

GISTs are the most common mesenchymal tumor found in the gastrointestinal tract. The utilization of imatinib, and now second generation tyrosine kinase inhibitors, for targeted therapy is a novel paradigm for treating solid tumors. Radiographic and pathologic evaluations are vital to diagnosis and prognosis of GIST. Surgical resection of primary, recurrent, and metastatic GIST, in combination with tyrosine kinase inhibition is the standard of care for treating patients with GIST. A multidisciplinary approach to GIST diagnosis and treatment is essential for successful outcomes.

\section{References}

1. Nilsson B, Bumming P, Meis-Kindblom JM, et al. Gastrointestinal stromal tumors: the incidence, prevalence, clinical course, and prognostication in the preimatinib mesylate era--a population-based study in western Sweden. Cancer. 2005; 103(4):821-9. [PubMed: 15648083]

2. DeMatteo RP, Lewis JJ, Leung D, Mudan SS, Woodruff JM, Brennan MF. Two hundred gastrointestinal stromal tumors: recurrence patterns and prognostic factors for survival. Annals of surgery. 2000; 231(1):51-8. [PubMed: 10636102]

3. Kim TW, Lee H, Kang YK, et al. Prognostic significance of c-kit mutation in localized gastrointestinal stromal tumors. Clin Cancer Res. 2004; 10(9):3076-81. [PubMed: 15131046]

Surg Clin North Am. Author manuscript; available in PMC 2016 September 02. 
4. Martin J, Poveda A, Llombart-Bosch A, et al. Deletions affecting codons 557-558 of the c-KIT gene indicate a poor prognosis in patients with completely resected gastrointestinal stromal tumors: a study by the Spanish Group for Sarcoma Research (GEIS). J Clin Oncol. 2005; 23(25):6190-8. [PubMed: 16135486]

5. Wu TJ, Lee LY, Yeh CN, et al. Surgical treatment and prognostic analysis for gastrointestinal stromal tumors (GISTs) of the small intestine: before the era of imatinib mesylate. BMC gastroenterology. 2006; 6:29. [PubMed: 17062131]

6. Bumming P, Ahlman H, Andersson J, Meis-Kindblom JM, Kindblom LG, Nilsson B. Populationbased study of the diagnosis and treatment of gastrointestinal stromal tumours. The British journal of surgery. 2006; 93(7):836-43. [PubMed: 16705644]

7. Katz SC, DeMatteo RP. Gastrointestinal stromal tumors and leiomyosarcomas. Journal of surgical oncology. 2008; 97(4):350-9. [PubMed: 18286477]

8. Lasota J, Miettinen M. KIT and PDGFRA mutations in gastrointestinal stromal tumors (GISTs). Seminars in diagnostic pathology. 2006; 23(2):91-102. [PubMed: 17193822]

9. Fletcher CD, Berman JJ, Corless C, et al. Diagnosis of gastrointestinal stromal tumors: A consensus approach. Human pathology. 2002; 33(5):459-65. [PubMed: 12094370]

10. Miettinen M, Lasota J. Gastrointestinal stromal tumors: review on morphology, molecular pathology, prognosis, and differential diagnosis. Archives of pathology \& laboratory medicine. 2006; 130(10):1466-78. [PubMed: 17090188]

11. Sandrasegaran K, Rajesh A, Rushing DA, Rydberg J, Akisik FM, Henley JD. Gastrointestinal stromal tumors: CT and MRI findings. European radiology. 2005; 15(7):1407-14. [PubMed: 15761716]

12. Miettinen M, Sobin LH, Lasota J. Gastrointestinal stromal tumors of the stomach: a clinicopathologic, immunohistochemical, and molecular genetic study of 1765 cases with longterm follow-up. The American journal of surgical pathology. 2005; 29(1):52-68. [PubMed: 15613856]

13. Goerres GW, Stupp R, Barghouth G, et al. The value of PET, CT and in-line PET/CT in patients with gastrointestinal stromal tumours: long-term outcome of treatment with imatinib mesylate. European journal of nuclear medicine and molecular imaging. 2005; 32(2):153-62. [PubMed: 15690223]

14. Miettinen M, Lasota J. Gastrointestinal stromal tumors: pathology and prognosis at different sites. Seminars in diagnostic pathology. 2006; 23(2):70-83. [PubMed: 17193820]

15. Blay P, Astudillo A, Buesa JM, et al. Protein kinase C theta is highly expressed in gastrointestinal stromal tumors but not in other mesenchymal neoplasias. Clin Cancer Res. 2004; 10(12 Pt 1): 4089-95. [PubMed: 15217944]

16. Ng EH, Pollock RE, Munsell MF, Atkinson EN, Romsdahl MM. Prognostic factors influencing survival in gastrointestinal leiomyosarcomas. Implications for surgical management and staging. Annals of surgery. 1992; 215(1):68-77. [PubMed: 1731651]

17. Miettinen M, Sobin LH. Gastrointestinal stromal tumors in the appendix: a clinicopathologic and immunohistochemical study of four cases. The American journal of surgical pathology. 2001; 25(11):1433-7. [PubMed: 11684962]

18. Singer S, Rubin BP, Lux ML, et al. Prognostic value of KIT mutation type, mitotic activity, and histologic subtype in gastrointestinal stromal tumors. J Clin Oncol. 2002; 20(18):3898-905. [PubMed: 12228211]

19. Ma Y, Cunningham ME, Wang X, Ghosh I, Regan L, Longley BJ. Inhibition of spontaneous receptor phosphorylation by residues in a putative alpha-helix in the KIT intracellular juxtamembrane region. The Journal of biological chemistry. 1999; 274(19):13399-402. [PubMed: 10224103]

20. Shiu MH, Farr GH, Papachristou DN, Hajdu SI. Myosarcomas of the stomach: natural history, prognostic factors and management. Cancer. 1982; 49(1):177-87. [PubMed: 7053814]

21. Shiu MH, Farr GH, Egeli RA, Quan SH, Hajdu SI. Myosarcomas of the small and large intestine: a clinicopathologic study. Journal of surgical oncology. 1983; 24(1):67-72. [PubMed: 6887940]

Surg Clin North Am. Author manuscript; available in PMC 2016 September 02. 
22. Rudolph P, Gloeckner K, Parwaresch R, Harms D, Schmidt D. Immunophenotype, proliferation, DNA ploidy, and biological behavior of gastrointestinal stromal tumors: a multivariate clinicopathologic study. Human pathology. 1998; 29(8):791-800. [PubMed: 9712419]

23. Cooper PN, Quirke P, Hardy GJ, Dixon MF. A flow cytometric, clinical, and histological study of stromal neoplasms of the gastrointestinal tract. The American journal of surgical pathology. 1992; 16(2):163-70. [PubMed: 1733349]

24. Gunther T, Schneider-Stock R, Hackel C, et al. Telomerase activity and expression of hTRT and hTR in gastrointestinal stromal tumors in comparison with extragastrointestinal sarcomas. Clin Cancer Res. 2000; 6(5):1811-8. [PubMed: 10815902]

25. Ng EH, Pollock RE, Romsdahl MM. Prognostic implications of patterns of failure for gastrointestinal leiomyosarcomas. Cancer. 1992; 69(6):1334-41. [PubMed: 1540870]

26. McGrath PC, Neifeld JP, Lawrence W Jr. Kay S, Horsley JS 3rd, Parker GA. Gastrointestinal sarcomas. Analysis of prognostic factors. Annals of surgery. 1987; 206(6):706-10. [PubMed: 3689007]

27. Akwari OE, Dozois RR, Weiland LH, Beahrs OH. Leiomyosarcoma of the small and large bowel. Cancer. 1978; 42(3):1375-84. [PubMed: 81101]

28. Mol CD, Dougan DR, Schneider TR, et al. Structural basis for the autoinhibition and STI-571 inhibition of c-Kit tyrosine kinase. The Journal of biological chemistry. 2004; 279(30):31655-63. [PubMed: 15123710]

29. Verweij J, Casali PG, Zalcberg J, et al. Progression-free survival in gastrointestinal stromal tumours with high-dose imatinib: randomised trial. Lancet. 2004; 364(9440):1127-34. [PubMed: 15451219]

30. Heinrich MC, Corless CL, Blanke CD, et al. Molecular correlates of imatinib resistance in gastrointestinal stromal tumors. J Clin Oncol. 2006; 24(29):4764-74. [PubMed: 16954519]

31. Joensuu H, Dimitrijevic S. Tyrosine kinase inhibitor imatinib (STI571) as an anticancer agent for solid tumours. Annals of medicine. 2001; 33(7):451-5. [PubMed: 11680792]

32. Heinrich MC, Corless CL, Demetri GD, et al. Kinase mutations and imatinib response in patients with metastatic gastrointestinal stromal tumor. J Clin Oncol. 2003; 21(23):4342-9. [PubMed: 14645423]

33. Debiec-Rychter M, Sciot R, Le Cesne A, et al. KIT mutations and dose selection for imatinib in patients with advanced gastrointestinal stromal tumours. Eur J Cancer. 2006; 42(8):1093-103. [PubMed: 16624552]

34. Corless CL, Schroeder A, Griffith D, et al. PDGFRA mutations in gastrointestinal stromal tumors: frequency, spectrum and in vitro sensitivity to imatinib. J Clin Oncol. 2005; 23(23):5357-64. [PubMed: 15928335]

35. Blay JY, Le Cesne A, Ray-Coquard I, et al. Prospective multicentric randomized phase III study of imatinib in patients with advanced gastrointestinal stromal tumors comparing interruption versus continuation of treatment beyond 1 year: the French Sarcoma Group. J Clin Oncol. 2007; 25(9): 1107-13. [PubMed: 17369574]

36. Blay JY, Bonvalot S, Casali P, et al. Consensus meeting for the management of gastrointestinal stromal tumors. Report of the GIST Consensus Conference of 20-21 March 2004, under the auspices of ESMO. Ann Oncol. 2005; 16(4):566-78. [PubMed: 15781488]

37. DeMatteo R, Antonescu CR, Chadaram V, et al. Adjuvant imatinib mesylate in patients with primary high risk gastrointestinal stromal tumor (GIST) following complete resection: Safety results from the U.S. Intergroup Phase II trial (ACOSOG Z9000). J Clin Oncol. 2005; 23:9009.

38. Dematteo, RPOK.; Antonescu, CR., et al. Efficacy of adjuvant imatinib mesylate following complete resection of localized, primary gastrointestinal stromal tumor (GIST) at high risk of recurrence: the U.S. Intergroup phase II trial ACOSOG Z9000. [Abstract]. American Society of Clinical Oncology 2008 Gastrointestinal Cancers Symposium; Orlando, FL. January, 2008; p. A-8January, 2008

39. DeMatteo RPOK, Maki R, et al. Adjuvant imatinib mesylate increases recurrence free survival (RFS) in patients with completely resected localized primary gastrointestinal stromal tumor (GIST): North American Intergroup phase III trial ACOSOG Z9001. [Abstract]. J Clin Oncol. 2007; 25(Suppl 18):A10079. 
40. DeMatteo RP, Shah A, Fong Y, Jarnagin WR, Blumgart LH, Brennan MF. Results of hepatic resection for sarcoma metastatic to liver. Annals of surgery. 2001; 234(4):540-7. discussion 7-8. [PubMed: 11573047]

41. van Oosterom AT, Judson I, Verweij J, et al. Safety and efficacy of imatinib (STI571) in metastatic gastrointestinal stromal tumours: a phase I study. Lancet. 2001; 358(9291):1421-3. [PubMed: 11705489]

42. Demetri GD, von Mehren M, Blanke CD, et al. Efficacy and safety of imatinib mesylate in advanced gastrointestinal stromal tumors. The New England journal of medicine. 2002; 347(7): 472-80. [PubMed: 12181401]

43. Blanke CD, Demetri GD, von Mehren M, et al. Long-term results from a randomized phase II trial of standard-versus higher-dose imatinib mesylate for patients with unresectable or metastatic gastrointestinal stromal tumors expressing KIT. J Clin Oncol. 2008; 26(4):620-5. [PubMed: 18235121]

44. Raut CP, Posner M, Desai J, et al. Surgical management of advanced gastrointestinal stromal tumors after treatment with targeted systemic therapy using kinase inhibitors. J Clin Oncol. 2006; 24(15):2325-31. [PubMed: 16710031]

45. DeMatteo RP, Maki RG, Singer S, Gonen M, Brennan MF, Antonescu CR. Results of tyrosine kinase inhibitor therapy followed by surgical resection for metastatic gastrointestinal stromal tumor. Annals of surgery. 2007; 245(3):347-52. [PubMed: 17435539]

46. Desai J, Shankar S, Heinrich MC, et al. Clonal evolution of resistance to imatinib in patients with metastatic gastrointestinal stromal tumors. Clin Cancer Res. 2007; 13(18 Pt 1):5398-405. [PubMed: 17875769]

47. Hasegawa J, Kanda T, Hirota S, et al. Surgical interventions for focal progression of advanced gastrointestinal stromal tumors during imatinib therapy. International journal of clinical oncology / Japan Society of Clinical Oncology. 2007; 12(3):212-7.

48. Wen PY, Yung WK, Lamborn KR, et al. Phase I/II study of imatinib mesylate for recurrent malignant gliomas: North American Brain Tumor Consortium Study 99-08. Clin Cancer Res. 2006; 12(16):4899-907. [PubMed: 16914578]

49. Demetri GD, van Oosterom AT, Garrett CR, et al. Efficacy and safety of sunitinib in patients with advanced gastrointestinal stromal tumour after failure of imatinib: a randomised controlled trial. Lancet. 2006; 368(9544):1329-38. [PubMed: 17046465]

50. Von Mehren M. Imatinib-refractory gastrointestinal stromal tumors: the clinical problem and therapeutic strategies. Curr Oncol Rep. 2006; 8:192-7. [PubMed: 16618383]

51. Dileo PR,R, Vansonnenberg E, et al. Safety and efficacy of percutaneous radio-frequency ablation (RFA) in patients with metastatic gastrointestinal stromal tumor (GIST) with clonal evolution of lesions refractory to imatinib mesylate. J Clin Oncol. 2004; 22:9024.

52. Kobayashi K, Gupta S, Trent JC, et al. Hepatic artery chemoembolization for 110 gastrointestinal stromal tumors: response, survival, and prognostic factors. Cancer. 2006; 107(12):2833-41. [PubMed: 17096432]

53. Maluccio MA, Covey AM, Schubert J, et al. Treatment of metastatic sarcoma to the liver with bland embolization. Cancer. 2006; 107(7):1617-23. [PubMed: 16955508]

54. Dematteo RP, Heinrich MC, El-Rifai WM, Demetri G. Clinical management of gastrointestinal stromal tumors: before and after STI-571. Human pathology. 2002; 33(5):466-77. [PubMed: 12094371]

55. Edmonson JH, Marks RS, Buckner JC, Mahoney MR. Contrast of response to dacarbazine, mitomycin, doxorubicin, and cisplatin (DMAP) plus GM-CSF between patients with advanced malignant gastrointestinal stromal tumors and patients with other advanced leiomyosarcomas. Cancer investigation. 2002; 20(5-6):605-12. [PubMed: 12197215]

56. Von Burton G, Rankin C, Zalupski MM, Mills GM, Borden EC, Karen A. Phase II trial of gemcitabine as first line chemotherapy in patients with metastatic or unresectable soft tissue sarcoma. American journal of clinical oncology. 2006; 29(1):59-61. [PubMed: 16462504]

57. Blair SC, Zalupski MM, Baker LH. Ifosfamide and etoposide in the treatment of advanced soft tissue sarcomas. American journal of clinical oncology. 1994; 17(6):480-4. [PubMed: 7977164] 
58. Trent JC, Beach J, Burgess MA, et al. A two-arm phase II study of temozolomide in patients with advanced gastrointestinal stromal tumors and other soft tissue sarcomas. Cancer. 2003; 98(12): 2693-9. [PubMed: 14669291]

59. Joensuu H, De Braud F, Coco P, et al. Phase II, open-label study of PTK787/ZK222584 for the treatment of metastatic gastrointestinal stromal tumors resistant to imatinib mesylate. Ann Oncol. 2008; 19(1):173-7. [PubMed: 17698976]

60. Rossi F, Ehlers I, Agosti V, et al. Oncogenic Kit signaling and therapeutic intervention in a mouse model of gastrointestinal stromal tumor. Proceedings of the National Academy of Sciences of the United States of America. 2006; 103(34):12843-8. [PubMed: 16908864]

61. Wong NA, Young R, Malcomson RD, et al. Prognostic indicators for gastrointestinal stromal tumours: a clinicopathological and immunohistochemical study of 108 resected cases of the stomach. Histopathology. 2003; 43(2):118-26. [PubMed: 12877726]

62. van Oosterom AT, Judson IR, Verweij J, et al. Update of phase I study of imatinib (STI571) in advanced soft tissue sarcomas and gastrointestinal stromal tumors: a report of the EORTC Soft Tissue and Bone Sarcoma Group. Eur J Cancer. 2002; 38(Suppl 5):S83-7. [PubMed: 12528778]

63. Benjamin RSRC, Fletcher C, et al. Phase III dose-randomized study of imatinib mesylate (ST1571) for GIST: Intergroup S0033 early results. Proc Am Soc Clin Oncol. 2003; 22:814. 


\section{Synopsis}

Gastrointestinal stromal tumor (GIST) has been recognized as a unique tumor only in the last decade. Although rare as a clinical entity, there is much interest in the pathology and treatment because the KIT protooncogene mutation common to most GISTs can be inhibited by imatinib mesylate. Diagnosing and treating GIST requires a multidisciplinary approach, given the combination of pathologic and radiographic evaluation, surgical treatment, and oncologic care required to successfully treat patients with GIST 

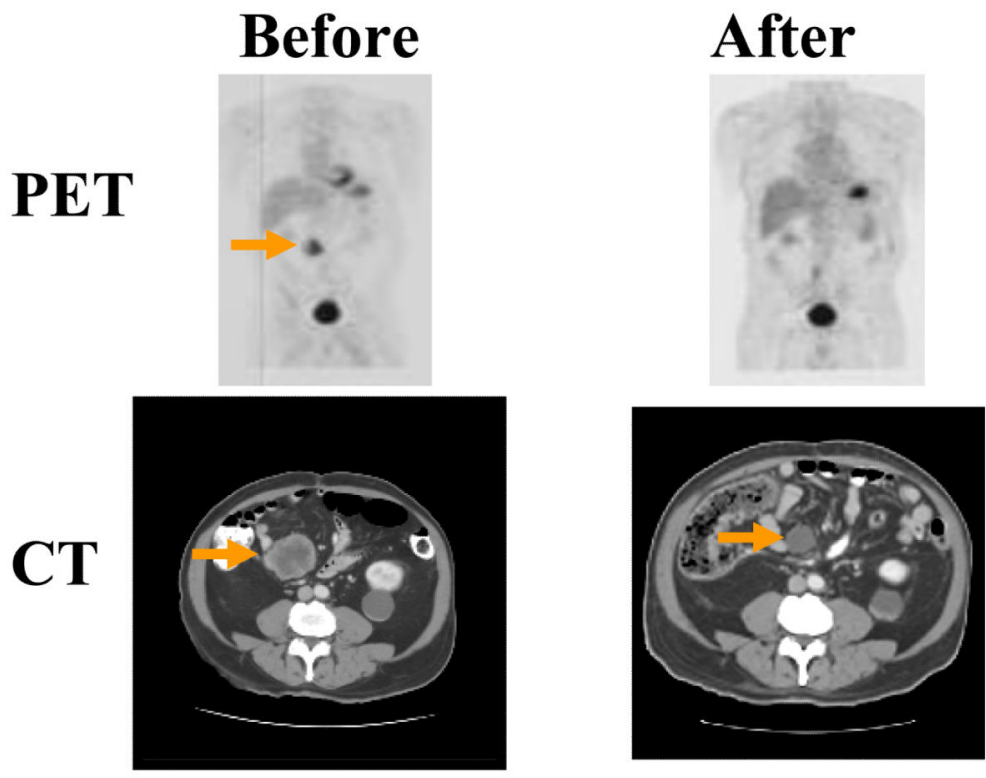

Figure 1.

PET scan response of recurrent GIST to imatinib. The peritoneal recurrence (lower left) had increased uptake of PET scan (upper left). Imatinib was used for several weeks, and there was a partial response, with a reduction in tumor size (lower right) and absence of PET uptake (upper right). From DeMatteo, Ann Surg Onc 9:831, 2002 with permission. 


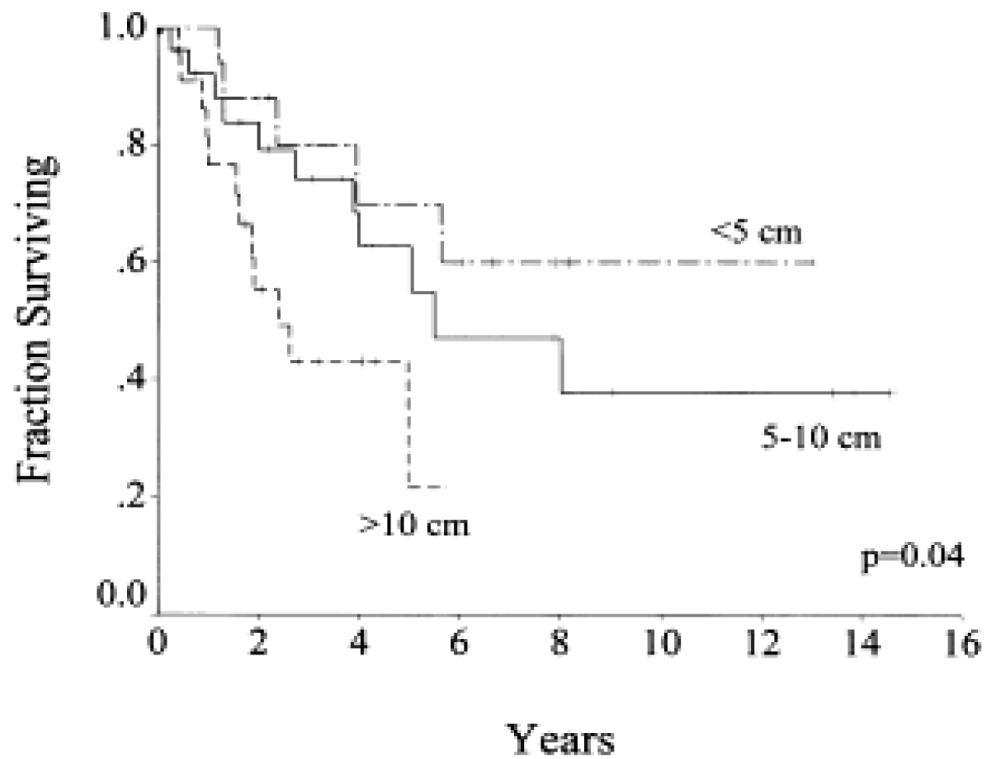

Figure 2.

Disease-specific survival and tumor size after complete resection of primary GIST $(n=80)$. From DeMatteo, et al Ann Surg 231:51 2000 with permission. 


\begin{tabular}{|c|c|c|c|c|}
\hline $\begin{array}{l}\text { Author } \\
\text { Kingham }\end{array}$ & & \begin{tabular}{|l|l|} 
ISBN $\#$ \\
J131117
\end{tabular} & \multirow{2}{*}{\multicolumn{2}{|c|}{ 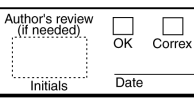 }} \\
\hline Fig.:\# & \multicolumn{2}{|c|}{$\begin{array}{l}\text { Document name } \\
\text { J13117-03.eps }\end{array}$} & & \\
\hline \multicolumn{2}{|c|}{$\begin{array}{l}\text { Artist } \\
\text { Marie Dean }\end{array}$} & Date $10 / 4 / 08$ & CE's review & \\
\hline $\mathrm{B} \times \mathrm{W}$ Х & 4/C $\square$ & enc $\square$ & & \\
\hline
\end{tabular}

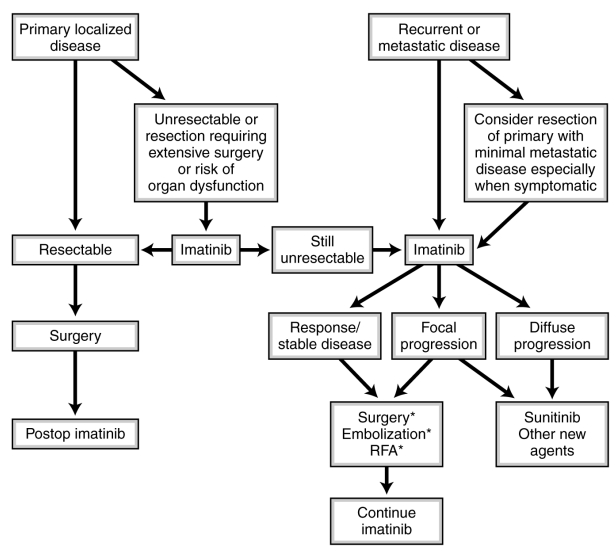

RFA = Radiofrequency ablation

* If all gross disease or all imatinib-resistant disease is treatable

Figure 3.

GIST treatment algorithm. From Gold and DeMatteo, Ann Surg 244:176, 2006 with permission. 


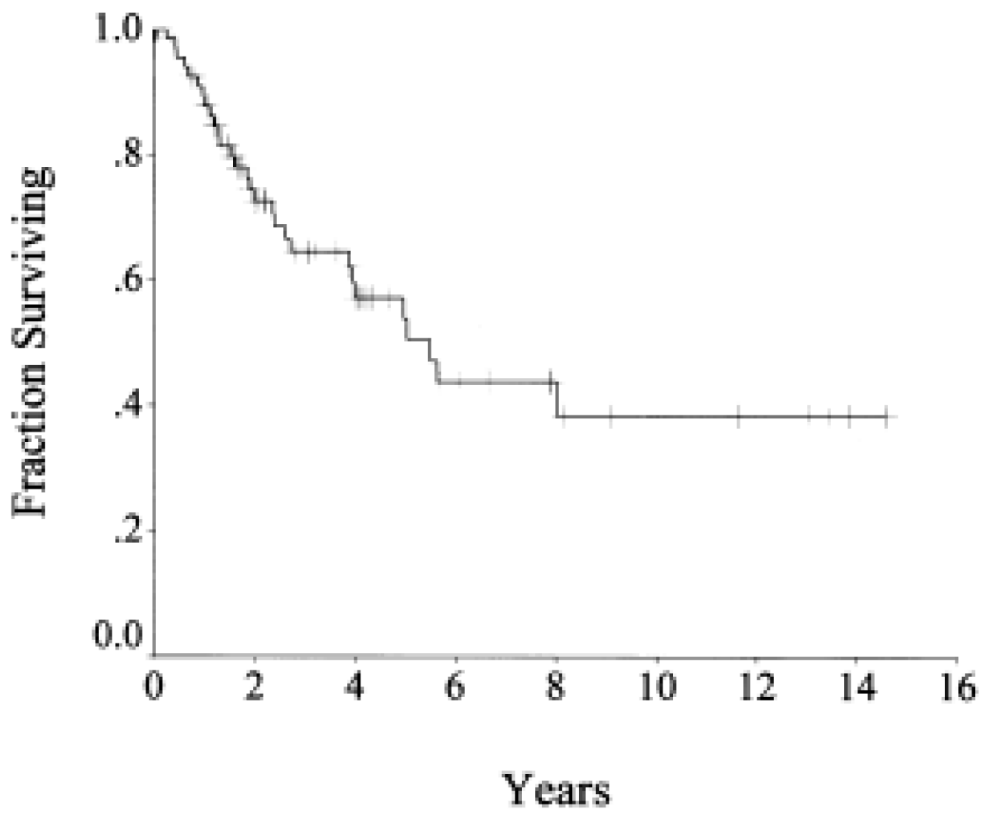

Figure 4.

Disease-specific survival after complete resection of primary GIST $(n=80)$. From DeMatteo, et al Ann Surg 231:51 2000 with permission. 


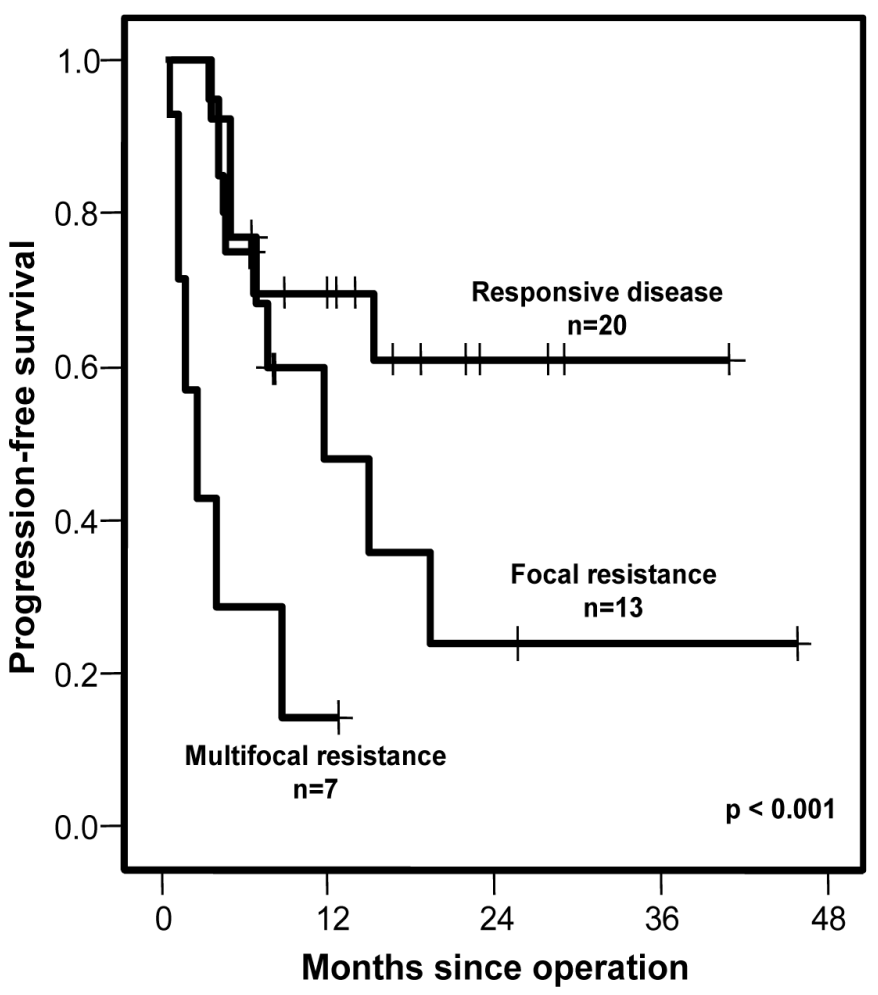

Figure 5.

Progression-free survival after imatinib treatment and metastatic GIST resection. From Dematteo, et al Ann Surg 245(3):347, 2007 with permission. 


\section{Table 1}

Rates of metastases or tumor related death in GISTs of stomach and small intestine by tumors grouped by mitotic rate and tumor size. From Miettenin, Lasotta, Sem in Diagnostic Pathology 23:70, 2006 with permission.

\begin{tabular}{|c|c|c|c|c|c|c|}
\hline \multicolumn{3}{|c|}{ Tumor Parameters } & \multicolumn{4}{|c|}{$\begin{array}{l}\% \text { of patients with progressive disease during long-term follow } \\
\text { up and characterization of risk for metastasis }\end{array}$} \\
\hline Group & Size & Mitotic Rate & Gastric GISTS & Jejunal and ileal GISTS & Duodenal GISTS & Rectal GISTS \\
\hline 1 & $\underline{s c m}$ & $\$$ per $50 \mathrm{HPFs}$ & 0 none & 0 none & 0 none & 0 none \\
\hline 2 & $>2 \mathrm{~cm} 5 \mathrm{~cm}$ & 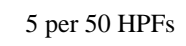 & 1.9 very low & 4.3 low & 8.3 low & 8.5 low \\
\hline $3 \mathbf{a}$ & $>5 \mathrm{~cm} \unlhd 0 \mathrm{~cm}$ & 5 per $50 \mathrm{HPFs}$ & 3.6 low & 24 moderate & & \\
\hline $3 \mathbf{b}$ & $>10 \mathrm{~cm}$ & $\checkmark$ per 50 HPFs & 12 moderate & 52 high & $34 \operatorname{high}^{\dagger}$ & $57 \mathrm{high}^{\dagger}$ \\
\hline 4 & $\underline{\mathrm{cm}}$ & $>5$ per $50 \mathrm{HPFs}$ & 0 & 50 & & 54 high \\
\hline 5 & $>2 \mathrm{~cm} 5 \mathrm{~cm}$ & $>5$ per $50 \mathrm{HPFs}$ & 16 moderate & 73 high & 50 high & 52 high \\
\hline $6 a$ & $>5 \mathrm{~cm} \unlhd 0 \mathrm{~cm}$ & $>5$ per $50 \mathrm{HPFs}$ & 55 high & 85 high & & \\
\hline $6 \mathbf{b}$ & $>10 \mathrm{~cm}$ & $>5$ per $50 \mathrm{HPFs}$ & 86 high & 90 high & 86 high $^{\dagger}$ & $71 \mathrm{high}^{\dagger}$ \\
\hline
\end{tabular}

Groups $3 \mathrm{a}$ and $3 \mathrm{~b}$ or $6 \mathrm{a}$ and $6 \mathrm{~b}$ are combined in duodenal and rectal GISTs because of small number of cases. 


\section{Table 2}

Outcome in large series of complete surgical resection of primary localized GIST. From Gold and DeMatteo, Ann Surg 244:176, 2006 with permission.

\begin{tabular}{|l|l|l|l|l|l|l|}
\hline Author & Year & $\begin{array}{l}\text { No. of } \\
\text { patients }\end{array}$ & $\begin{array}{l}\text { No. with } \\
\text { completely } \\
\text { resected } \\
\text { primary } \\
\text { localized } \\
\text { disease }\end{array}$ & $\begin{array}{l}\text { Median } \\
\text { follow-up } \\
\text { (months) }\end{array}$ & $\begin{array}{l}\text { Number with } \\
\text { recurrence } \\
(\%)\end{array}$ & $\begin{array}{l}\text { 5-year } \\
\text { survival }\end{array}$ \\
\hline DeMatteo $^{2}$ & 2000 & 200 & 80 & 24 & $32(40 \%)$ & $54 \%$ DSS \\
\hline Wong $^{61}$ & 2003 & 108 & 108 & 43 & & $42 \%$ OS, 29\%RFS \\
\hline Kim $^{3}$ & 2004 & 101 & 86 & 36 & $29(34 \%)$ & $78 \%$ OS \\
\hline Martin $^{4}$ & 2005 & 162 & 162 & 42 & $42(26 \%)$ & $68 \%$ RFS \\
\hline Wu $^{5}$ & 2006 & 100 & 85 & 33 & $44(44 \%)$ & $44 \%$ DFS \\
\hline Bumming & 2006 & 259 & 221 & & $38(17 \%)$ & \\
\hline
\end{tabular}

DSS, disease-specific survival; OS, overall survival; RFS, recurrence-free survival; disease-free survival 
Table 3

Trials of imatinib mesylate in metastatic gist. From Gold and DeMatteo, Ann Surg 244:176, 2006 with permission.

\begin{tabular}{|c|c|c|c|c|c|c|c|c|}
\hline \multirow[t]{2}{*}{ Trial } & \multirow[t]{2}{*}{ Phase } & \multirow[t]{2}{*}{ Year } & \multirow{2}{*}{$\begin{array}{l}\text { Imatinib mesylate } \\
\text { dose (n) }\end{array}$} & \multirow[t]{2}{*}{ Follow-up } & \multicolumn{3}{|c|}{ Best response } & \multirow[t]{2}{*}{ Comments } \\
\hline & & & & & PR & SD & PD & \\
\hline EORTC $^{41,62}$ & I & 2001,2002 & $\begin{array}{l}400,600,800, \text { or } \\
1000 \mathrm{mg} / \mathrm{d}(35)\end{array}$ & 8-12 months & $51 \%$ & $31 \%$ & $8 \%$ & $\begin{array}{l}\text { TTR }=1 \text { week } \\
\mathrm{MTD}=800 \mathrm{mg} / \text { day }\end{array}$ \\
\hline U.S. Multicenter ${ }^{42,43}$ & II & 2002,2004 & $\begin{array}{l}400 \mathrm{mg} / \mathrm{d}(73) \\
600 \mathrm{mg} / \mathrm{d}(74)\end{array}$ & 34 months & $\begin{array}{l}67 \% \\
66 \%\end{array}$ & $\begin{array}{l}16 \% \\
18 \%\end{array}$ & $\begin{array}{l}17 \% \\
8 \%\end{array}$ & $\begin{array}{l}\text { No difference between } \\
\text { groups }\end{array}$ \\
\hline EORTC $^{29}$ & III & 2003 & $\begin{array}{l}400 \mathrm{mg} / \mathrm{d}(470) \\
800 \mathrm{mg} / \mathrm{d}(472)\end{array}$ & 2 years & $\begin{array}{l}50 \% \\
54 \%\end{array}$ & $\begin{array}{l}32 \% \\
32 \%\end{array}$ & $\begin{array}{l}13 \% \\
9 \%\end{array}$ & $\begin{array}{l}32 \% \text { Grade III-IV toxicity } \\
50 \% \text { Grade III-IV toxicity } \\
\text { Improved PFS for } \\
800 \mathrm{mg} / \mathrm{d}(\mathrm{p}=0.03)\end{array}$ \\
\hline Intergroup ${ }^{63}$ & III & 2003 & $\begin{array}{l}400 \mathrm{mg} / \mathrm{d} \mathrm{(350)} \\
800 \mathrm{mg} / \mathrm{d}(352)\end{array}$ & 12 months & $\begin{array}{l}49 \% \\
48 \%\end{array}$ & $\begin{array}{l}22 \% \\
22 \%\end{array}$ & & $\begin{array}{l}36 \% \text { Grade III-IV toxicity } \\
52 \% \text { Grade III-IV toxicity } \\
\text { No difference in PFS }\end{array}$ \\
\hline
\end{tabular}

$\mathrm{PR}=$ partial response, $\mathrm{SD}=$ stable disease, $\mathrm{PD}=$ progressive disease, $\mathrm{TTR}=$ time to recurrence, $\mathrm{MTD}=$ maximal tolerated dose, $\mathrm{CR}=$ complete response, $\mathrm{PFS}=$ progression-free survival 